Terr. Atmos. Ocean. Sci., Vol. 17, No. 4, 815-828, December 2006

\title{
Mapping the Thickness of the Gas Hydrate Stability Zone in the South China Sea
}

\author{
Shuhong Wang ${ }^{1,3}$, Wen Yan ${ }^{1,3, *}$, and Haibin Song ${ }^{2,3}$ \\ (Manuscript received 24 September 2005, in final form 5 October 2006)
}

\begin{abstract}
Many researchers have estimated the thickness of the gas hydrate stability zone (GHSZ) and amount of gas hydrate at different areas in the South China Sea (SCS) using varying methods, but few have reported calculations for the whole of the SCS. In this paper, Milkov and Sassen's model is used to calculate the thickness of the GHSZ in the SCS. In addition, an estimation of the amount of gas hydrate and discussed in terms of gas composition and the effects of water depth. Average thicknesses for the GHSZ in the SCS are estimated to be $\sim 440 \mathrm{~m}, \sim 477 \mathrm{~m}$ and $\sim 553 \mathrm{~m}$ based on the relationship between GHSZ thickness and water depth established in this study for 3 kinds of gas hydrates with gas composition containing $100 \%$ methane, $96 \%$ methane, and $90 \%$ methane, respectively. Then, by assuming that gas hydrates are distributed in half of the continental slope area of the SCS, and that the gas hydrate saturation is $1.2 \%$ of sediment volume, the amounts of gas hydrate are estimated to be $\sim 3.2 \times 10^{12} \mathrm{~m}^{3}, \sim 3.4 \times 10^{12} \mathrm{~m}^{3}$, $\sim 4.0 \times 10^{12} \mathrm{~m}^{3}$, and the volumes of hydrate-bound gases are $\sim 5.2 \times 10^{14} \mathrm{~m}^{3}$, $\sim 5.6 \times 10^{14} \mathrm{~m}^{3}, \sim 6.5 \times 10^{14} \mathrm{~m}^{3}$ for the 3 kinds of gas hydrates above, respectively. The results above show that water depth and gas composition are important factors affecting the thickness of the GHSZ in which the thickness of the GHSZ increases with water depth and decreases with the volume of methane, and that the gas hydrate may be a potential energy source in SCS.
\end{abstract}

(Key words: Gas hydrate, Thickness of gas hydrate stability zone, South China Sea)

\footnotetext{
${ }^{1}$ CAS Key Laboratory of Marginal Sea Geology, South China Sea Institute of Oceanology, Chinese Academy of Sciences, Guangzhou, China

2 Institute of Geology and Geophysics, Chinese Academy of Sciences, Beijing, China

${ }^{3}$ Guangzhou Center for Gas Hydrate Research, Chinese Academy of Sciences, Guangzhou, China

* Corresponding author address: Dr. Wen Yan, CAS Key Laboratory of Marginal Sea Geology, South China Sea Institute of Oceanology, Chinese Academy of Sciences, Guangzhou, China; E-mail: wyan@scsio.ac.cn
} 


\section{INTRODUCTION}

Gas hydrates are solid ice-like structures formed at low temperature and high pressure by van der Waals forces between gas and water molecules. Under such conditions water molecules acting as a "host" effectively form a molecular cage trapping the "guest" gas molecules via electrostatic forces (Sloan 1998). In a marine environment, gas hydrates composed principally of methane can be found in the shallow ocean geosphere where the appropriate conditions of low temperature and high pressure along with an adequate supply of methane combine with water contained in the pore spaces of marine sediments (Kvenvolden 1993). By 2002, geological, geophysical, and geochemical evidence of gas hydrates had been reported from 81 localities worldwide. These localities varied widely from onshore Arctic regions to offshore passive and active margins, inland seas, and lakes. However, intact gas hydrate samples have been recovered at only 22 of these localities (Mikov and Sassen 2002), mainly offshore.

The main driving force in gas hydrate research is the common assumption that the global gas hydrate inventory contains a huge amount of methane carbon (Kvenvolden 1999). However, the global estimates of hydrate-bound gas in marine sediments vary by several orders of magnitude and are thought to be highly uncertain (Kvenvolden 1999; Lerche 2000). The most widely cited estimate of global hydrate-bound gas is $21 \times 10^{15} \mathrm{~m}^{3}$ of methane at standard temperature and pressure (or $10000 \mathrm{Gt}$ of methane carbon) (Kvenvolden 1999), which is proposed as a "consensus value" from several independent estimations. This large gas hydrate reservoir is further suggested as an important component of the global carbon cycle (Dickens 2001; Kvenvolden 2002) and as a potential future energy source (Collett 2002). At present, the global estimate of hydrate-bound gas that best reflects the current knowledge of submarine gas hydrate is in the range of $(1 \sim 5) \times 10^{15} \mathrm{~m}^{3}$ (or $500-2500 \mathrm{Gt}$ of methane carbon) (Milkov 2004).

The SCS is one of the biggest marginal seas in the western Pacific. At present, the general viewpoint is that there are abundant gas hydrates in the continental slope of the SCS. Many researchers (Yao 2001; Fang et al. 2002; Zeng et al. 2003; Chen et al. 2004; Chi et al. 2006) have calculated the thickness of the gas hydrate stability zone (GHSZ) and amount of gas hydrate at different areas in the SCS using a variety of methods, but few have made calculations estimating the thickness and amount of gas hydrate contained in the whole of the SCS (Jin and Wang 2002). In this paper, Milkov and Sassen's (2001) model was adopted to calculate the thickness of the GHSZ and the amount of gas hydrate for the whole SCS. Such an estimation ought be conducive to further study of gas hydrate in the region and provide additional information for other researchers.

\section{GEOLOGICAL SETTING}

The SCS (Fig. 1), covering an area of $350 \times 10^{4} \mathrm{~km}^{2}$, is one of the biggest marginal seas in the western Pacific. The sea floor topography appears ladder-like form from edge to center. It is $1212 \mathrm{~m}$ deep on average with a maximum depth of $5377 \mathrm{~m}$. The complicated morphology of the SCS given its widely dispersed platforms, plateaus, trough valleys and island reefs, is suitable for accumulation of sediments and preservation of organic matters. The thickness of 


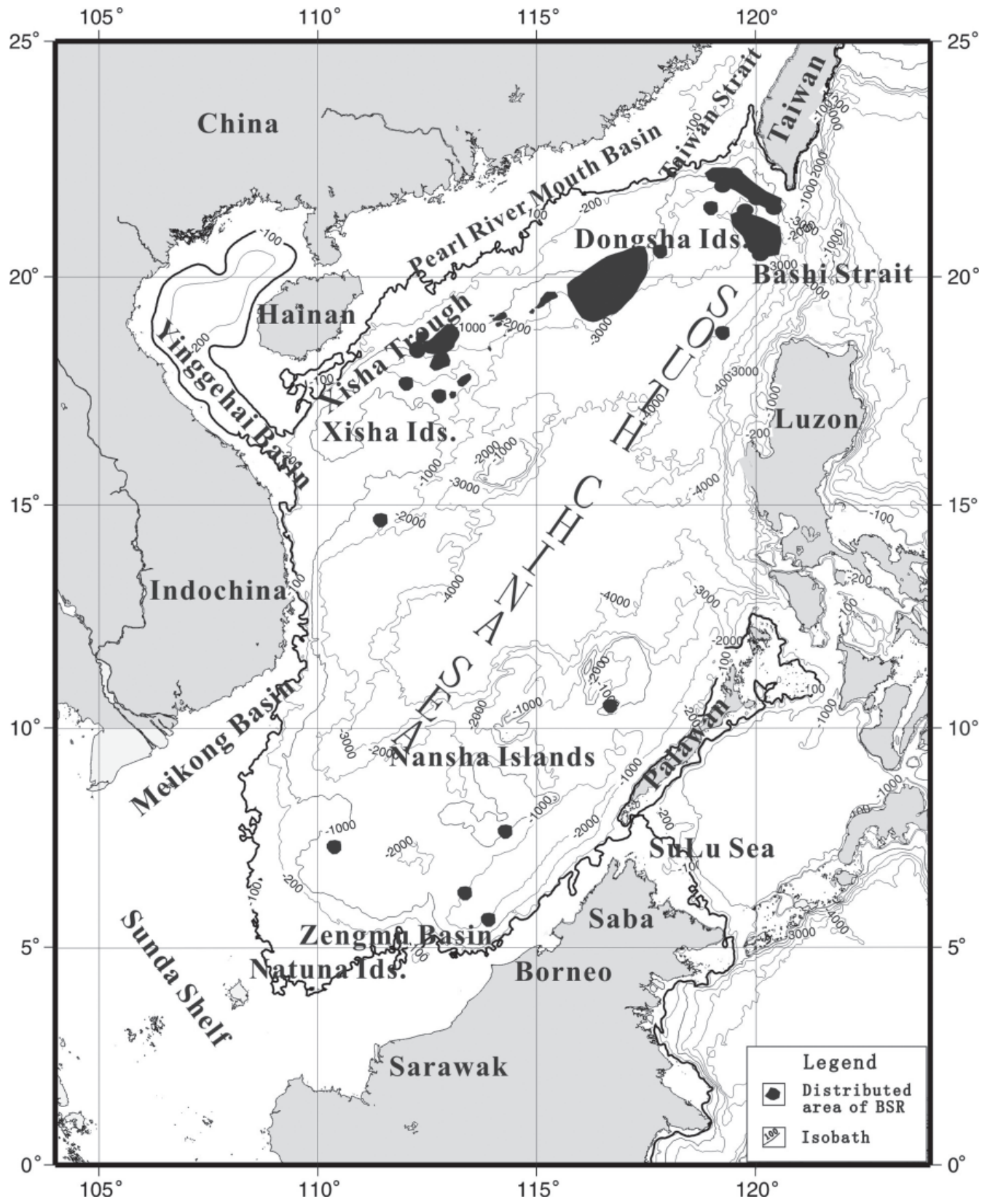

Fig. 1. Map showing the geographical location of the South China Sea (The calculation area of the GHSZ is at a depth of $300 \sim 3500$ m under water. BSR areas and sites from Zhu et al. (2001b), Wu et al. (2004), Wu et al. (2005), Chi et al. (1998), Yang et al. (2006), and Deng et al. (2006)). 
sediments in the SCS is more than $500 \mathrm{~m}$ and the maximum reaches $10000 \mathrm{~m}$. It is also rich in oil and gas resources (Zhang et al. 2002; Wu et al. 2003).

Its widely distributed sedimentary basins, favorable water depths, good organic matter supply, mud diapers, and fault structures, as revealed in seismic profiles, indicate advantageous conditions for gas hydrate formation in the SCS (Zhu et al. 2001a; Chen et al. 2004; Liu et al. 2006; Yan et al. 2006). The BSR (bottom simulating reflector) in the Nansha Trough of the southern SCS was discovered early in 1984 based on seismic data; BSRs are mainly located at between 300 - $600 \mathrm{~m}$ below the seabed in the southeast slop of the Nansha Trough in 1500 2800 m of water (Berner and Faber 1992). In 1998, a BSR in the north SCS was reported (Yao 1998). Hereafter, many studies were conducted on the distribution, minerogenetic conditions and perspective of gas hydrates in the region (Wu et al. 2000; Chen et al. 2001; Song et al. 2001; Yao 2001; Zhu et al. 2001b; Zhang et al. 2002; Ma et al. 2002; Chen et al. 2006; Cheng et al. 2006; Schnürle et al. 2006; Yang et al. 2006).

In the SCS, gas hydrate mainly occurs in the continental slope, so the selected study area in this paper $\left(107 \sim 118^{\circ} \mathrm{E}\right.$ and $5 \sim 22^{\circ} \mathrm{N}$ ) covers an area under $300 \sim 3500 \mathrm{~m}$ of water (Yu et al. 2004) (Fig. 1).

\section{THE THICKNESS OF THE GHSZ AND AMOUNT OF GAS HYDRATE}

\subsection{Estimation of the Thickness of the GHSZ}

The GHSZ is a specific range of pressure and temperature conditions in the subsurface within which gas hydrate is stable (Booth et al. 1998). Water depth, bottom water temperature, pressure and thermal gradients in sediments, pore water salinity and gas availability and composition are among the variables that affect the thickness of the GHSZ. In addition, gas hydrate stability may also be affected by the texture and mineralogy of the encasing sediments (Clennell et al. 1999). Milkov and Sassen $(2001,2003)$ have put forward quantitative models describing these effects, and applied them to calculate the thickness of GHSZ in Gulf of Mexico.

The bathymetry of the study area is shown in Fig. 1. Figure 2 shows the relationship between the water depths and bottom water temperatures in the SCS. It can be seen from Fig. 2 that the bottom water temperature in the SCS ranges from $15 \sim 20^{\circ} \mathrm{C}$ at depths of $100 \sim 200 \mathrm{~m}$ and decreases to $4 \sim 5^{\circ} \mathrm{C}$ when the water depth reaches more than $1000 \mathrm{~m}$.The relationship between water depth and bottom water temperature can be expressed as:

$$
\mathrm{T}_{\mathrm{w}}=373.41 \times \mathrm{B}^{-0.6269},
$$

where $\mathrm{T}_{\mathrm{w}}$ is bottom water temperature $\left({ }^{\circ} \mathrm{C}\right)$ and $\mathrm{B}$ represents the water depth in meters below sea level (mbsl).

The geothermal gradient is not uniform in the SCS and tends to increase with water depth. On the northwestern continental slope, it varies generally within the range of $32-40{ }^{\circ} \mathrm{C} \mathrm{km}^{-1}$, with an average value of $37.6^{\circ} \mathrm{C} \mathrm{km}^{-1}$ (Yao et al. 1994; Spanger and Hayes 1995). Spanger and Hayes (1995) estimated using linear regression that the geothermal gradient here lies between 


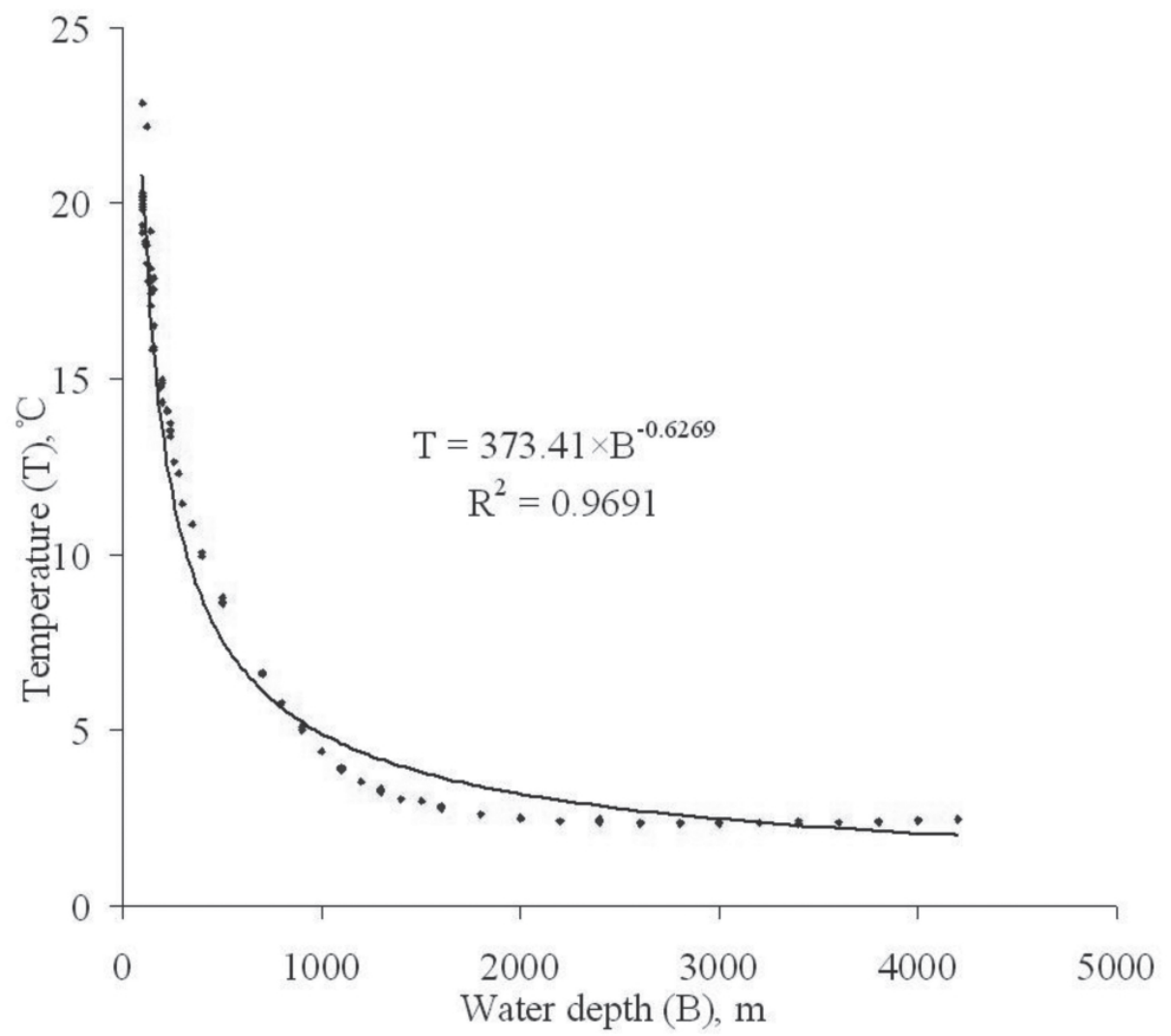

Fig. 2. Plot of bottom water temperature vs. water depth in SCS (The dots represent the measured values of bottom water temperature; the solid line is the simulating curve based on the values of bottom water temperature and water depths; $\mathrm{R}$ is the correlation coefficient between the bottom water temperature and water depth. All the data are from https: //128. 160.23.42/gdemv/gdemv.html).

23.6 and $41.6{ }^{\circ} \mathrm{C} \mathrm{km}^{-1}$. In the Pearl River Mouth Basin, it is generally $30-40{ }^{\circ} \mathrm{C} \mathrm{km}^{-1}$ (Gong and Li 1997; Yao et al. 1994). In the western most Xisha Trough, the average geothermal gradient reaches $40{ }^{\circ} \mathrm{C} \mathrm{km}^{-1}$ based on seafloor heat flow measurement (Yao et al. 1994). This value is significantly higher than the average geothermal gradient $\left(35^{\circ} \mathrm{C} \mathrm{km}^{-1}\right)$ in the Pearl River Mouth Basin. Overall, the geothermal gradient increases gradually from the Zhujiangkou Basin to the Xisha Trough (Wu et al. 2005). Therefore, the geothermal gradient of the whole SCS was assumed to be $37.5^{\circ} \mathrm{C} \mathrm{km}^{-1}$ in this study. 
Change in pore water salinity in SCS is very small ( usually > 33\%) (Xue et al. 1991; Zeng and Zhou 2003; Chen et al. 2004), and was assumed to be 35\% in this study. Gas hydrate samples have not yet been collected in the SCS, but many studies (Zhu et al. 2001b; Lu et al. 2002; Lu et al. 2003; Wu et al. 2003; Wang et al. 2005; Zhu et al. 2005; Yang et al. 2006) suggest that there are gas hydrates in this area, and the gas sources include both thermogenic gas and biogenic gases. In this study, three kinds of gas hydrates of different gas molecular composition (Table 1) are used to represent biogenic, mixed and thermogenic gases in the SCS.

The equilibrium conditions for gas hydrate crystallization of pure methane and the other two hydrate-forming gases shown in Table 1 are calculated based on Sloan's (1998) CSMHYD Program (Fig. 3), where pore water salinity is assumed to be 35\%. The gas hydrate stability curves for the three different gas compositions can be fitted by the following three logarithmic functions, respectively (Fig. 3):

$$
\begin{aligned}
& \mathrm{T}_{\text {st_100 }}=9.1256 \times \operatorname{Ln}(\mathrm{D})-50.029, \\
& \mathrm{~T}_{\text {st_96 }}=7.3637 \times \operatorname{Ln}(\mathrm{D})-34.502, \\
& \mathrm{~T}_{\text {st_90 }}=7.0724 \times \operatorname{Ln}(\mathrm{D})-29.970,
\end{aligned}
$$

where $\mathrm{T}_{\mathrm{st}}$ is the temperature of gas hydrate stability $\left({ }^{\circ} \mathrm{C}\right)$ at depth $\mathrm{D}(\mathrm{m})$. The depth $\mathrm{D}$ was converted from pressure assuming a linear hydrostatic gradient $10 \mathrm{MPa} \mathrm{km}^{-1}$ in the water column and in sediments.

Temperature of sediments at any depth below seafloor can be defined from the combination of Eq. (1) (for bottom water temperature) and the assumed geothermal gradient:

$$
\mathrm{T}_{\mathrm{s}}=37.5 \times \mathrm{A} / 1000+373.41 \times \mathrm{B}^{-0.6269},
$$

where $\mathrm{T}_{\mathrm{s}}$ is the temperature in sediments at depth A below the seafloor (mbsf). The lower boundary of the GHSZ occurs at the intersection points of functions 5 and 2, 5 and 3 or 5 and 4, depending on gas composition. This problem can be solved by finding the zero of functions:

$$
\begin{aligned}
& f(B)=-37.5 \times C / 1000-373.41 \times B^{-0.6269}+9.1256 \times \operatorname{Ln}(C+B)-50.029 \\
& f(B)=-37.5 \times C / 1000-373.41 \times B^{-0.6269}+7.3637 \times \operatorname{Ln}(C+B)-34.502, \\
& f(B)=-37.5 \times C / 1000-373.41 \times B^{-0.6269}+7.0724 \times \operatorname{Ln}(C+B)-29.970
\end{aligned}
$$

where C is the thickness of the GHSZ (m). Newton's method was used to find the zero of these functions. The final results of the thicknesses of the GHSZ for the three kinds of gas compositions are shown in Fig. 4; these can be used to define the thickness of GHSZ at any specific water depth in the study area. This is a conceptual model in which some possible local changes 
Table 1. Molecular composition (vol \%) of hydrate-forming gases used to estimate gas hydrate stable conditions.

\begin{tabular}{cccc}
\hline Gas hydrate & $\mathrm{CH}_{4}$ & $\mathrm{C}_{2} \mathrm{H}_{6}$ & $\mathrm{C}_{3} \mathrm{H}_{8}$ \\
\hline A & 100 & - & - \\
B & 96 & 3 & 1 \\
C & 90 & 7 & 3 \\
\hline
\end{tabular}

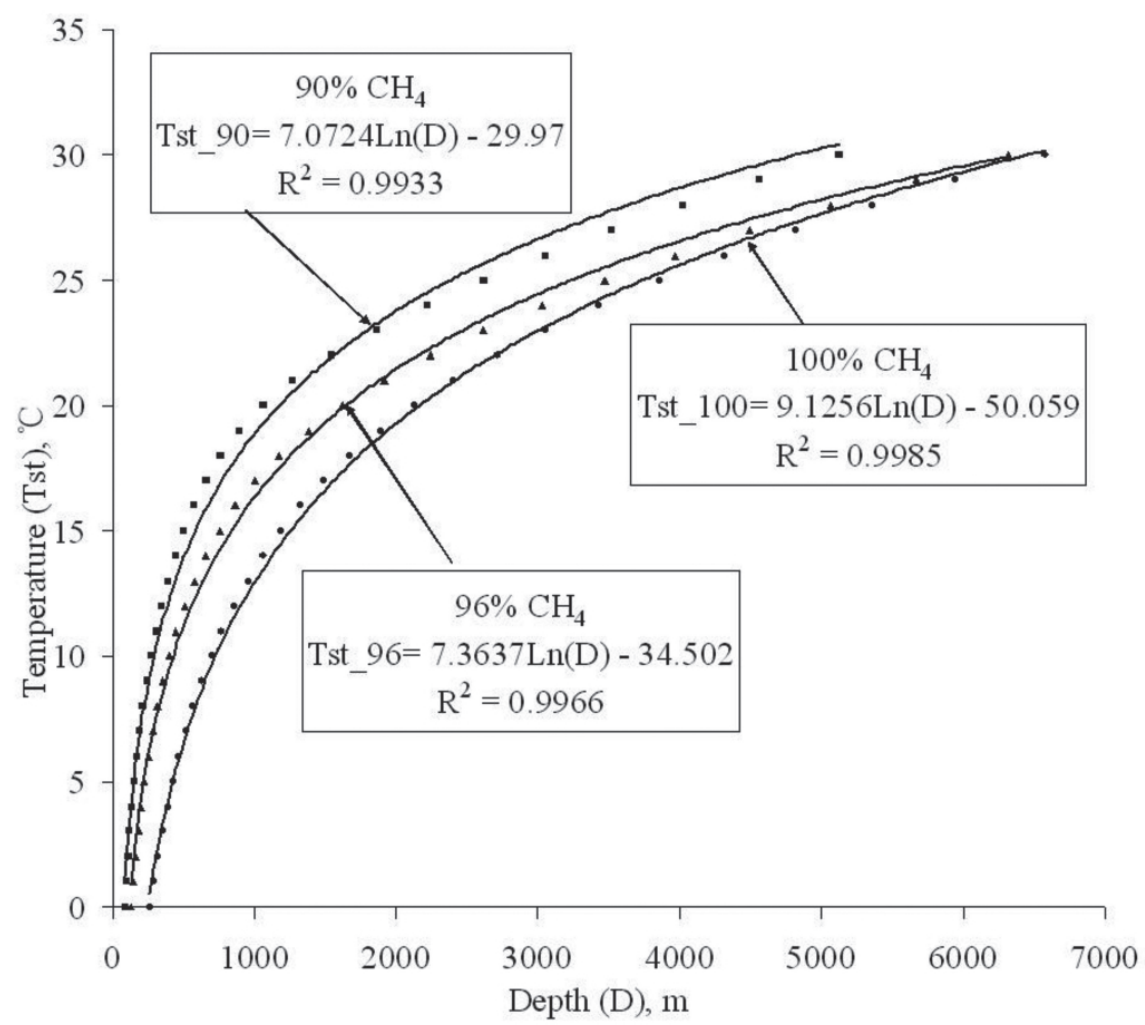

Fig. 3. Phase equilibrium curves for crystallization of gas hydrates in which gas is $100 \%$ methane (diamond), $96 \%$ methane (triangle), and $90 \%$ methane (square), respectively (the solid lines are the simulating curves based on the values of bottom water temperature and water depths for the 3 kinds of gas hydrates above, respectively; $\mathrm{R}$ is the correlation coefficient). 


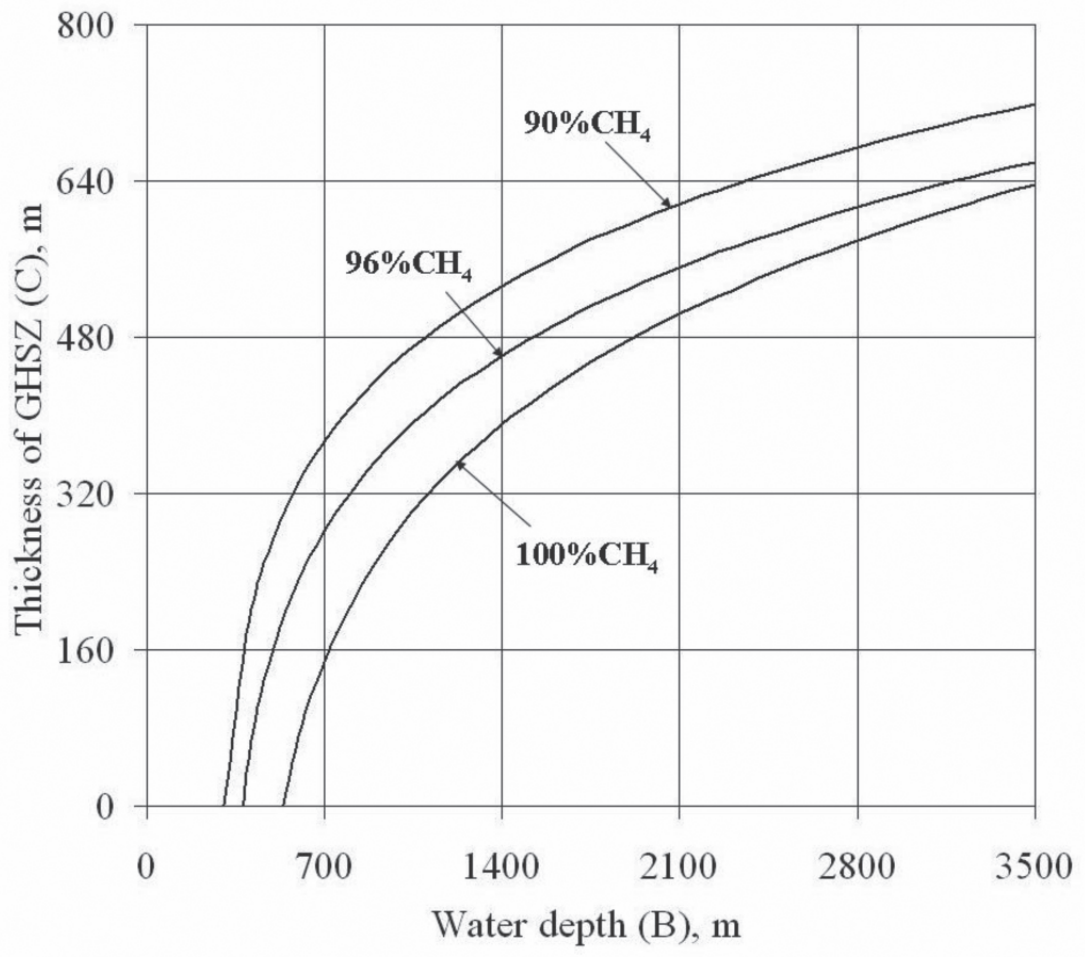

Fig. 4. Calculated thickness of the GHSZ vs. water depth in the study area for the 3 kinds of gas hydrates described in the text.

in sediments, such as the fluid temperature, pore water salinity, gas composition and flux rate et al., that may alter the theoretical values of the thickness of the GHSZ (Milkov and Sassen 2000), have not been taken into account.

Both the water depth and gas composition will affect the thickness of the GHSZ. It can be seen from Fig. 4 that the thickness of the GHSZ increases with water depth and shows a logarithmic relationship between them. When the water depth is fixed, the thickness of the GHSZ decreases with the volume of methane in the gas hydrate. Maps showing the calculated thickness of the GHSZ for gas hydrate crystallized with gas containing 100\%, 96\%, and 90\% $\mathrm{CH}_{4}$ respectively in the study area are also presented in Fig. 5

For the 3 kinds of gas hydrates used in this study, i.e., containing $100 \%$ methane, $96 \%$ methane, and $90 \%$ methane, the calculated thickness of the GHSZ following the relationship of the thickness of GHSZ and water depth in the SCS range from 0 to $649 \mathrm{~m}, 0$ to $686 \mathrm{~m}$, and 0 to $734 \mathrm{~m}$, with averaged thicknesses of $\sim 440 \mathrm{~m}, \sim 477 \mathrm{~m}$, and $\sim 553 \mathrm{~m}$, respectively. 

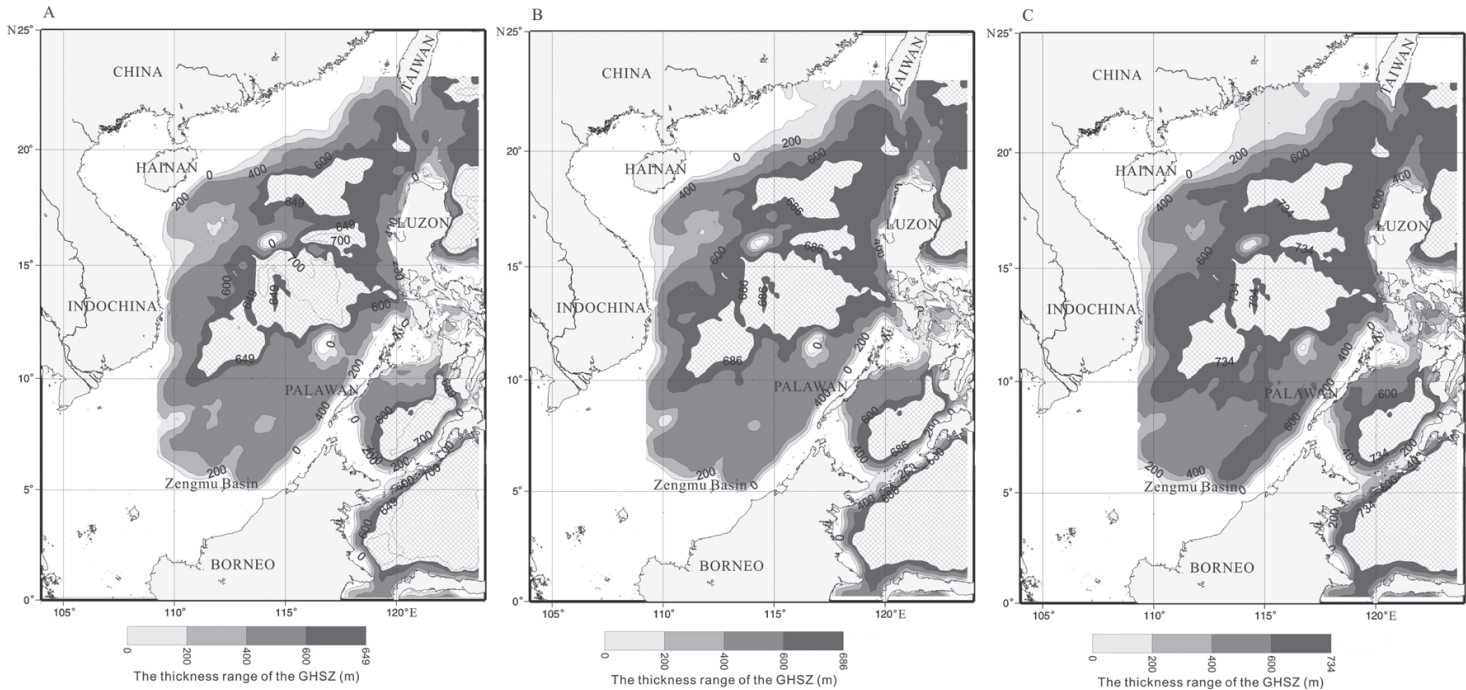

Fig. 5. Maps of the calculated thickness of the GHSZ (in meters) for gas hydrate crystallized from gas containing 100\% (A), $96 \%$ (B), and 90\% (C) $\mathrm{CH}_{4}$, respectively in the study area (the water depth of gridded regions is $>$ $3500 \mathrm{~m})$.

\subsection{Estimation of Gas Hydrate Amount}

The amount of gas hydrate in the SCS can be determined by Eq. (9):

$$
V=M \times \Delta Z \times S
$$

where $V$ is the volume of gas hydrate $\left(\mathrm{m}^{3}\right), M$ is the distribution area of gas hydrate $\left(\mathrm{km}^{2}\right), \Delta Z$ is the average thickness of the gas hydrate stability zone $(\mathrm{m})$, and $S$ represents the saturation of gas hydrate in sediments (\%). Milkov (2004) suggested that global average gas hydrate saturation is $\sim 0.9-1.5 \%$ of sediment volume, a medium value, i.e., $1.2 \%$, was assumed for calculation in this study.

The volume of hydrate-bound gases $(Q)$ in gas hydrate (the gas volume in gas hydrate under standard conditions) can be expressed as:

$$
Q=V \times E \text {, }
$$

where $V$ is the volume of gas hydrate $\left(\mathrm{m}^{3}\right)$, and $E$ represents the gas hydrate yield, given here at its theoretical value of 164 (Satoh et al. 1996). 
Equations (10) and (11) can be used to estimate the amount of gas hydrate and the volume of hydrate-bound gases for the SCS. The area of the SCS is $350 \times 10^{4} \mathrm{~km}^{2}$, but conditions of temperature and pressure in many areas of SCS are not suitable for the formation of gas hydrate . Gas hydrate usually exists in the continental slope (Thomas 1979), and the area of continental slope in the SCS is about $120 \times 10^{4} \mathrm{~km}^{2}$. If gas hydrate occurred in half of the continental slope area of the SCS (Yu et al. 2004), that area would be about $60 \times 10^{4} \mathrm{~km}^{2}$. Based on the estimated thickness of the GHSZ in the SCS and the equations (10) and (11) above, the amount of gas hydrate can be obtained to be $\sim 3.2 \times 10^{12} \mathrm{~m}^{3}, \sim 3.4 \times 10^{12} \mathrm{~m}^{3}, \sim 4.0 \times 10^{12} \mathrm{~m}^{3}$, and the volume of hydrate-bound gases to be $\sim 5.2 \times 10^{14} \mathrm{~m}^{3}, \sim 5.6 \times 10^{14} \mathrm{~m}^{3}, \sim 6.5 \times 10^{14} \mathrm{~m}^{3}$ for gas hydrate crystallized from gas containing $100 \%, 96 \%$, and $90 \%$ of methane, respectively.

\section{CONCLUSIONS}

Milkov and Sassen's (2001) model was used to calculate the thickness of the GHSZ in the SCS. In addition, an estimation of the total amount of gas hydrate was undertaken for the same region and discussed in terms of water depth effects and the gas composition.

Water depth and the gas composition are two important factors affecting the thickness of the GHSZ. Thickness of the GHSZ increases with water depth and decreases with the volume of methane. A logarithmic relationship was observed between GHSZ thickness and water depth.

The average thicknesses of the GHSZ in SCS are estimated to be $\sim 440, \sim 477$, and $\sim 553 \mathrm{~m}$ based on the relationship between GHSZ thickness and water depth established in this study for 3 kinds of gas hydrates $\left(\mathrm{CH}_{4}, \mathrm{C}_{2} \mathrm{H}_{6}, \mathrm{C}_{3} \mathrm{H}_{8}\right)$ with gas composition containing $100 \%$ methane, $96 \%$ methane, and $90 \%$ methane, respectively. Then, by assuming that gas hydrates are distributed in half of the continental slope area in the SCS, and that the gas hydrate saturation is $1.2 \%$ of sediment volume, the amounts of gas hydrate are estimated to be $\sim 3.2 \times 10^{12} \mathrm{~m}^{3}$, $\sim 3.4 \times 10^{12} \mathrm{~m}^{3}, \sim 4.0 \times 10^{12} \mathrm{~m}^{3}$, and the volume of hydrate-bound gases are $\sim 5.2 \times 10^{14} \mathrm{~m}^{3}$, $\sim 5.6 \times 10^{14} \mathrm{~m}^{3}, \sim 6.5 \times 10^{14} \mathrm{~m}^{3}$ for gas hydrate crystallized from gas containing $100 \%, 96 \%$, and $90 \%$ of methane, respectively.

Combining the facts of a series of advantageous conditions, such as the widely distributed sedimentary basins, favorable water depth and a good matter supply, mud diapirs and fault structures, for gas hydrate formation in the SCS, it can be seen that gas hydrate may be a potential energy source in the SCS. Therefore, it is very important for more research to be conducted on the resource potential of gas hydrate in the SCS.

Acknowledgements This research was supported by the Innovation Program of the Chinese Academy of Sciences (Grant No. KZCX3-SW-224), National Science Foundation of China (Grant No. 40676043 and No. 40406011), and the foundation of Key Laboratory of Marginal Sea Geology, the South China Sea Institute of Oceanology, Chinese Academy of Sciences (Grant No. MSGL0509). We would like to thank Dr. X. B. Shi for providing the heat flow data of the South China Sea, and Drs. P. Yan, H. Deng, and H. H. Xu for their valuable suggestions regarding this paper. 


\section{REFERENCES}

Berner, U., and E. Faber, 1992: Hydrocarbon gases in surface sediments of the South China Sea. In: Jin, X., H. R. Kudrass, and G. Pautot (Eds.), Marine Geology and Geophysics of the South China Sea, China Ocean Press, Beijing, 199-211.

Booth, J. S., W. J. Winters, W. P. Dillon, M. B. Clennel, and M. M. Rowe, 1998: Major occurrences and reservoir concepts of marine clathrate hydrates: implications of field evidence. In: Henriet, J. P., and J. Mienert (Eds.), Gas Hydrates: Relevance to World Margin Stability and Climate Change, Geology Society London Special Publications, 137, 113-128.

Chen, D. F., B. C. Yao, Z. H. Zao, and W. X. Xu, 2001: Geochemistry constraints and potential distributions of gas hydrates in Pearl River Mouth Basin and Qiongdongnan Basin in the north margin of the South China Sea. Mar. Geol. Quat. Geol., 21, 73-78. (in Chinese)

Chen, D. F., X. X. Li, and B. Xia, 2004: Distribution of gas hydrate stable zones and resource prediction in the Qiongdongnan Basin of the South China Sea. Chin. J. Geophys., 47, 483-489. (in Chinese)

Chen, D. F., Z. Su, and L. M. Cathles, 2006: Types of gas hydrates in marine environments and their thermodynamic characteristics. Terr. Atmos. Ocean. Sci., 17, 723-737.

Cheng, W. B., C. S. Lee, C. S. Liu, P. Schnürle, S. S. Lin, and H. R. Tsai, 2006: Velocity structure in marine sediments with gas hydrate reflectors in offshore SW Taiwan, from OBS data tomography. Terr. Atmos. Ocean. Sci., 17, 739-756.

Chen, H. Z., and D. Zhou, 1997: The study of gas hydrates and its relation with global changes. Adv. Earth-Sci., 12, 37-42. (in Chinese)

Chi, W. C., D. L. Read, C. S. Liu, and N. Lundberg, 1998: Distribution of the bottom-simulation reflector in the offshore Taiwan collision Zone. Terr. Atmos. Ocean. Sci., 9, 779-794.

Chi, W. C., D. L. Reed, and C. C. Tsai, 2006: Gas hydrate stability zone in offshore southern Taiwan. Terr. Atmos. Ocean. Sci., 17, 829-843.

Clennell, M. B., M. Hovland, J. S. Booth, P. Henru, and W. J. Winters, 1999: Formation of natural gas hydrates in marine sediments 1 . Conceptual model of gas hydrate growth conditioned by host sediment properties. J. Geophys. Res., 104, 22985-23003.

Collett, T. S., 2002: Energy resource potential of natural gas hydrates. AAPG Bull., 86, 19711992.

Deng, X. G., S. Y. Fu, Y. Y. Huang, G. X. Zhang, N. Y. Wu, and L. S. Wu, 2006: Geochemical characteristics of sediments at site HD196 in Dongsha Islands, the North of the South China Sea, and their implication for gas hydrates. Geoscience, 20, 92-102. (in Chinese)

Dickens, G. R., 2001: Modeling the global carbon cycle with a gas hydrate capacitor: significance for the latest Paleocene thermal maximum. In: Paull, C. K., and W. P. Dillon (Eds.), Natural Gas Hydrates: Occurrence, Distribution, and Detection, AGU, Geophysical Monograph Series, 124, 19-40.

Fang, Y. X., H. G. Shentu, and X. L. Jin, 2002: Computation of thickness of hydrate stability zone in Okinawa Trough. Miner. Depos., 21, 414-418. (in Chinese) 
Gong, Z. S., and S. T. Li, 1997: Continental margin basin analysis and hydrocarbon accumulation in the Northern South China Sea. Science Press, Beijing, 510 pp. (in Chinese)

Jin, C. S., and J. Y. Wang, 2002: A preliminary study of the gas hydrate stability zone in the South China Sea. Acta Geol. Sin.-Engl., 76, 423-428.

Kvenvolden, K. A., 1993: Gas hydrates-geological perspective and global change. Rev. Geophys., 31, 173-187.

Kvenvolden, K. A., 1999: Potential effects of gas hydrate on human welfare. Proc. Natl. Acad. Sci., 96, 3420-3426.

Kvenvolden, K. A., 2002: Methane hydrate in the global organic carbon cycle. Terr. Nova, 14, 302-306.

Lerche, I., 2000: Estimates of worldwide gas hydrate resource. Energy Explor. Exploit., 18, 329-337.

Liu, C. S., P. Schnürle, Y. Wang, S. H. Chung, S. C. Chen, and T. H. Hsiuan, 2006: Distribution and characters of gas hydrate offshore of southwestern Taiwan. Terr. Atmos. Ocean. Sci., 17, 615-644.

Lu, B., F. Y. Zhang, W. Y. Zhang, H. Y. Jin, and B. H. Wu, 2003: The Study of acidolytical hydrocarbon in sediment as an indicator of oil-gas in the East Area of the South China Sea. Acta Oceanol. Sin., 25, 79-88. (in Chinese)

Lu, Z. Q., B. H. Wu, and Y. H. Zhu, 2002: Preliminary discussion on origin and formation of potential gas hydrates in South China Sea. Miner. Depos., 21, 232-239. (in Chinese)

Ma, Z. T., J. H. Geng, L. G. Dong, and H. B. Song, 2002: Seismic recognition studies on marine gas hydrate. Mar. Geol. Quat. Geol., 22, 1-8. (in Chinese)

Milkov, A. V., 2004: Global estimates of hydrate-bound gas in marine sediments: how much is really out there? Earth-Sci.Rev., 66, 183-197.

Milkov, A. V., and R. Sassen, 2000: Thickness of the gas hydrate stability zone, Gulf of Mexico contimental slope. Mar. Petrol. Geol., 18, 981-991.

Milkov, A. V., and R. Sassen, 2001: Estimate of gas hydrate resource, northwestern Gulf of Mexico continental slope. Mar. Geol., 179, 71-83.

Milkov, A. V., and R. Sassen, 2002: Economic geology of offshore gas hydrate accumulations and provinces. Mar. Petrol. Geol. 19, 1-11.

Milkov, A. V., and R. Sassen, 2003: Two-dimensional modeling of gas hydrate decomposition in the northwestern Gulf of Mexico: significance to global change assessment. Global Planet. Change, 36, 31-46.

Satoh, M., T. Maekawa, and Y. Okuda, 1996: Estimation of amount of methane and resources of natural gas hydrates in the world and around Japan. J. Geol. Soc. Jpn., 102, 959-971.

Schnürle, P., C. S. Liu, and C. S. Lee, 2006: Acoustic and shear-wave velocities in hydratebearing sediments offshore southwestern Taiwan: tomography, converted waves analysis and reverse-time migration of OBS records. Terr. Atmos. Ocean. Sci., 17, 757-779.

Sloan, E. D., 1998: Clathrate hydrates of natural gases. $2^{\text {nd }}$ Ed., Marcel-Dekker, New York, $705 \mathrm{pp}$.

Song, H. B., J. H. Geng, H. K. Wong, W. S. Zhang, Y. X. Fang, T. Y. Hao, and W. W. Jiang, 2001: A preliminary study of gas hydrates in Dongsha region north of South China Sea. Chin. J. Geophys., 44, 687-694. (in Chinese) 
Spanger, N. S., and D. E. Hayes, 1995: Gravity, heat flow, and seismic constraints on the processes of crust extension: northern margin of the South China Sea. J. Geophys. Res., 100, 22447-22483.

Thomas, H. S., 1979: Seismic evidence for widespread possible gas hydrates horizons on continental slopes and rises. AAPG Bull., 63, 2204-2213.

Wang, J. Q., Y. H. Zhu, B. H. Wu, and N. Q. Fang, 2005: Geochemistry of hydrocarbon gases from site 1146, ODP Leg 184, the South China Sea and the implications. Mar. Geol. Quat. Geol., 25, 53-60. (in Chinese)

Wu, B. H., Y. H. Zhu, J. Q. Wang, B. Y. Chen, and G. X. Zhang, 2000: Gas hydrate in the South China Sea: Reviews and prospect. EOS Trans. AGU, 81, 66.

Wu, B. H., G. X. Zhang, Y. H. Zhu, Z. Q. Lu, and B. Y. Chen, 2003: Progress of gas hydrate investigation in China offshore. Earth-Sci. Front., 10, 177-189. (in Chinese)

Wu, S. G., G. X. Zhang, C. S. Guo, Y. Y. Huang, and S. J. Zhong, 2004: Geological constraint on the distribution of gas hydrate in the Dongsha continental slope of South China Sea. Acta Petrol. Sin., 25, 7-12. (in Chinese)

Wu, S., G. Zhang, Y. Huang, J. Liang, and H. K. Wong, 2005: Gas hydrate occurrence on the continental slope of the northern South China Sea. Mar. Petrol. Geol., 22, 403-412.

Xue, W. J., C. L. Huo, and G. X. Si, 1991: The paleoclimate and paleoceanography of late quaternary in northern South China Sea. Mar. Geol. Res., 4, 1-96. (in Chinese)

Yan, P., H. Deng, and H. Liu, 2006: The geological structure and prospect of gas hydrate over the Dongsha Slope, South China Sea. Terr. Atmos. Ocean. Sci., 17, 645-658.

Yang, T. F., P. C. Chuang, S. Lin, J. C. Chen, Y. Wang, and S. H. Chung, 2006: Methane venting in gas hydrate potential area offshore of SW Taiwan: evidence of gas analysis of water column samples. Terr. Atmos. Ocean. Sci., 17, 933-950.

Yang, T., S. Y. Jiang, L. Ge, J. H. Yang, H. F. Ling, N. Y. Wu, G. X. Zhang, J. Liu, and D. H. Chen, 2006: Geochemical characteristics of sediment pore water from site XS-01 in the Xisha Trough of South China Sea and their significance for gas hydrate occurrence. Quat. Sci., 26, 442-448. (in Chinese)

Yao, B. C., 1998: Preliminary exploration of gas hydrate in the northern margin of the South China Sea. Mar. Geol. Quat. Geol., 18, 11-18. (in Chinese)

Yao, B. C., 2001: The gas hydrate in the South China Sea. J. Trop. Oceanogr., 20, 20-28. (in Chinese)

Yao, B. C., W. J. Zeng, D. E. Hayes, and S. Spanger, 1994: The Geological Memoir of South China Sea Surveyed Jointly by China and USA. China Univ. Geosci. Press, Wuhan, 1102. (in Chinese)

Yu, X. H., Z. J. Zhang, X. Su, F. Chen, and Y. Li, 2004: Primary discussion on accumulation conditions for sedimentation of gas hydrate and its distribution in South China Sea. Earth-Sci. Front., 11, 311-315. (in Chinese)

Zeng, W. P., and D. Zhou, 2003: GIS-aided estimation of gas hydrate resources in Southern South China Sea. J. Trop. Oceanogr., 22, 35-45. (in Chinese)

Zhang, G. X., Y. X. Huang, Y. H. Zhu, and B. H. Wu, 2002: Prospect of gas hydrate resources in the South China Sea. Mar. Geol. Quat. Geol., 22, 75-81. (in Chinese)

Zhu, Y. H., B. H. Wu, and Z. Q. Lu, 2001a: The prospecting for gas hydrate offshore China. Miner. Depos., 20, 174-180. (in Chinese) 
Zhu, Y. H., G. X. Zhang, Z. Q. Lu, B. Y. Chen, and B. H. Wu, 2001b: Gas hydrate in the South China Sea: background and indicators. Acat Petrol. Sin., 22, 6-10. (in Chinese)

Zhu, Y. H., Z. Rao, J. Liu, Y. L. Liu, and R. M. Bai, 2005: Geochemical anomalies and their implication from site 14, the Xisha Trough, the South China Sea. Geoscience, 19, 3944. (in Chinese)

Wang, S., W. Yen, and H. Song, 2006: Mapping the thickness of the gas hydrate stability zone in the South China Sea. Terr. Atmos. Ocean. Sci., 17, 815-828. 